\title{
Construct validity and internal consistency of the Brazilian version of Leisure Attitude Measurement for the elderly*
}

\author{
Validade de constructo e consistência interna da versão brasileira \\ da Leisure Attitude Measurement para idosos \\ Validez de constructo y consistencia interna de la versión brasileña \\ de Leisure Attitude Measurement para los ancianos
}

How to cite this article:

Castro VC, Radovanovic CAT, Dellaroza MSG, Pedroso B, Silva ES, Carreira L. Construct validity and internal consistency of the Brazilian version of Leisure Attitude Measurement for the elderly. Rev Esc Enferm USP. 2021;55:e03710. doi: https://doi.org/10.1590/S1980-220X2020000703710

\author{
Vivian Carla de Castro ${ }^{1}$ \\ Cremilde Aparecida Trindade \\ Radovanovic ${ }^{2}$ \\ (iD) Mara Solange Gomes Dellaroza ${ }^{3}$ \\ Bruno Pedroso 4 \\ Eraldo Schunk Silva ${ }^{5}$ \\ Lígia Carreira ${ }^{2}$ \\ * Extracted from the thesis: "Adaptação \\ transcultural e avaliação das propriedades \\ psicométricas da Leisure Attitude \\ Measurement para a pessoa idosa", \\ Universidade Estadual de Maringá, 2019. \\ 1 Centro Universitário de Campo \\ Mourão, Departamento de Medicina, \\ Campo Mourão, PR, Brazil. \\ 2 Universidade Estadual de Maringá, \\ Departamento de Enfermagem, \\ Maringá, PR, Brazil. \\ 3 Universidade Estadual de Londrina, \\ Departamento de Enfermagem, \\ Londrina, PR, Brazil. \\ ${ }^{4}$ Universidade Estadual de Ponta \\ Grossa, Departamento de Educação \\ Física, Ponta Grossa, PR, Brazil. \\ 5 Universidade Estadual de Maringá, \\ Departamento de Estatística, \\ Maringá, PR, Brazil.
}

\section{ABSTRACT}

Objective: To evaluate the construct validity and internal consistency of the Brazilian version of Leisure Attitude Measurement for the elderly. Method: Methodological study with a quantitative approach. The data were collected for three months through domiciliary visits to a random and representative sample of 384 elders. The internal consistency was measured through Cronbach alpha coefficient. Construct validity was evaluated through exploratory factor analysis. Factor extraction was conducted per principal components, following the Kaiser criterion, with rotation through Varimax solution. Results: The participants' mean age was 70,9 and they were mostly women, married, living with relatives, with one to four years of education, and with an income of up to one minimum wage. The final model of the instrument has conserved three factors, under the parsimony criterion, explaining $50 \%$ of data variance, with a total of 27 items distributed across the cognitive, affective, and behavioral domains, with an overall Cronbach alpha coefficient of 0.89 . Conclusion: The proposed structural model has shown construct validity and an appropriate internal consistency, explaining 50\% of data variability. Its application can promote the understanding of social reality and encourage a positive attitude and elderly engagement in leisure activities.
\end{abstract}

\section{DESCRIPTORS}

Aged; Leisure Activities; Quality of Life; Health of the Elderly; Geriatric Nursing; Validation Study.
Corresponding author:

Vivian Carla de Castro

Rua Sebastião Domingos

Sabaini, 570B, Jardim Itália

CEP 87060-668 - Maringá, PR, Brazil

vivian.carla5@hotmail.com
Received: 01/09/2020

Approved: 09/23/2020 


\section{INTRODUCTION}

Leisure is a complex phenomenon whose comprehension is based on diverse approaches ${ }^{(1)}$. The leisure-work duality, which originated in the industrial society, defines leisure as a set of occupations in which individuals engage freely and disinterestedly after having complied with their social obligations. From a contemporary perspective, leisure may be conceived of as culture experienced during free time and as a human necessity ${ }^{(2-4)}$. Considering the multiple forms of satisfying this need, the meaning of leisure should not exclude work, but rather reflect their complementarity ${ }^{(2)}$.

The complementarity between leisure and work becomes clearer during age-related retirement, when individuals commonly have more free time due to the interruption or reduction of labor activities, being able to engage more frequently in pleasant activities. On the other hand, the process of retirement impacts the standards of activities, social contacts, and financial resources of individuals ${ }^{(5-7)}$ and - considering the enormous growth of the elderly population worldwide ${ }^{(5)}$ - adds to other financial, social, and health issues ${ }^{(8)}$. For these people, leisure habits established throughout life are particularly important, since leisure contributes to health, well-being, and management of time and negative life events, although it does not guarantee positive results ${ }^{(7)}$.

Leisure can be a means for the elderly to adapt to age-related changes either by maintaining their levels of activity and participation, substituting work, resignifying daily occurrences, or preserving valuable identity traits ${ }^{(9)}$. Concerning health, engagement in leisure activities is a key factor for successful aging ${ }^{(4)}$, as it promotes physical and mental health, social interactions, and quality of life while minimizing symptoms of depression and risk of cognitive and motor decline $e^{(7,10-12)}$ and increasing autonomy ${ }^{(8,11)}$, which makes this phenomenon significant for gerontological and geriatric nursing.

Attitude towards leisure activities is the main determinant of participation in and satisfaction with these activities. Individuals with positive attitudes are known to usually evaluate their leisure experiences positively ${ }^{(7)}$. Attitude towards leisure includes cognitive, affective, and behavioral components, which refer, respectively, to knowledge and beliefs, feelings, and behavioral patterns related to leisure ${ }^{(13)}$.

Given the importance of attitude for engagement in leisure and its evident benefits, the scarcity of suitable tools to evaluate this construct is emphasized ${ }^{(14)}$, mainly for the elder population ${ }^{(15)}$. Most instruments on this topic either restrict the conception of leisure to frequency of participation in activities, overlooking its subjective meaning ${ }^{(14)}$ or the amplitude of leisure contents, or are not available in Brazilian Portuguese ${ }^{(1)}$. Considering that standardized evaluation instruments are an integrating part of nursing research and practice ${ }^{(16)}$, the availability of a valid and trustworthy instrument to measure the attitudes of Brazilian elders towards leisure is relevant.

With the objective of measuring attitude towards leisure in its cognitive, affective, and behavioral components,
American authors have developed the Leisure Attitude Measurement (LAM $)^{(17)}$, which was adapted and validated for other countries, such as Korea, China, Iran, Turkey, and Portugal ${ }^{(13)}$. Its adaptation to the Brazilian culture is directed at the elderly population and was named $L A M-$ Versão Brasileira (LAM-VB); however, its psychometric qualities were yet to be tested. The objective of this study was to evaluate the construct validity and the internal consistency of LAM-VB for the elderly.

\section{METHOD}

\section{Design OF STUdy}

This is a quantitative methodological study.

\section{Population}

This research was conducted with elderly living in the municipality of Maringá, in the state of Paraná, Brazil, registered in the 33 Basic Health Units which had teams of the Family Health Strategy (Estratégia Saúde da Família - ESF). The Municipal Health Office has authorized the access to the digital register, which included circa 50,000 elders in 2017; this corresponds to $12.30 \%$ of the general population estimated for this period.

\section{SAMPLE}

During sampling, the rule for calculation of sample proportion was applied considering the finite population correction factor. The confidence level $(1-\alpha)$ was defined as $95 \%$ and error (e) was defined as 0.05 . A prevalence (p) of 0.5 was set, given that the literature review had not provided the expected prevalence in this case. Considering $\mathrm{N}=50,000$ elderly, $\mathrm{p}=0.5$, error $=0.05$, and $Z=1.96$, the calculated sample totaled 384 elderly.

\section{SeleCtion CRITERIA}

The sample was randomly selected based on digital records of people who were over 60 in 2017.

The inclusion criteria were being able to express clearly in Brazilian Portuguese, living in the urban area of the municipality, and having obtained a minimum score in the MiniMental State Examination (MMSE) according to education level ${ }^{(18)}$. The exclusion criteria were not being registered in the system, error in ESF register (incomplete or unavailable address and elder's name not corresponding to that of the resident of the informed address), change of residence, death, elder was not found at home after three attempts, and elder was unable to interact.

Each excluded elder was substituted based on a randomly ordered list of extra sample units. The ineligible elders exceeded the 96 (25\%) extra sample units included in the first random selection, mainly due to the data in the system not being up to date. Two other random selections of new extra sample units to match the calculated sample were thus required and were performed in different occasions (Figure 1). 


\begin{tabular}{|c|c|c|c|c|}
\hline 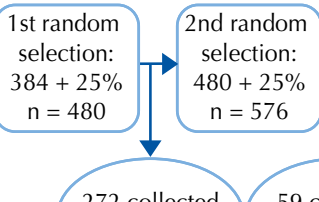 & $\longrightarrow \begin{array}{r}3 \text { rd rar } \\
\text { selec } \\
576+ \\
\mathrm{n}=\end{array}$ & \multicolumn{3}{|c|}{$\begin{array}{c}\text { TOTAL } \\
384 \text { collectec } \\
288 \text { lost }\end{array}$} \\
\hline Exclusion criteria & $\begin{array}{c}1 \text { st } \\
\text { random } \\
\text { selection }\end{array}$ & $\begin{array}{l}\text { 2nd } \\
\text { random } \\
\text { selection }\end{array}$ & $\begin{array}{c}\text { 3rd } \\
\text { random } \\
\text { selection }\end{array}$ & Total \\
\hline $\begin{array}{l}\text { Unable to communicate in } \\
\text { Portuguese }\end{array}$ & 02 & - & - & 02 \\
\hline Living in a rural area & 02 & 01 & - & 03 \\
\hline $\begin{array}{l}\text { Did not meet the MMSE } \\
\text { score }\end{array}$ & 09 & 04 & 03 & 16 \\
\hline Unregistered & 19 & 05 & 05 & 29 \\
\hline Register error & 52 & 10 & 07 & 69 \\
\hline Change of address & 30 & 03 & 04 & 37 \\
\hline Died & 08 & 04 & 01 & 13 \\
\hline $\begin{array}{l}\text { Not found after three } \\
\text { attempts }\end{array}$ & 37 & 03 & 10 & 50 \\
\hline Uncapable of interaction & 07 & 01 & 02 & 10 \\
\hline Total & 208 & 37 & 43 & 288 \\
\hline
\end{tabular}

Figure 1 - Steps for sample selection of elders in the study - Maringá, PR, Brazil, 2018.

A total of 53 elders have refused participation, two elderly have been excluded of the second random selection due to having been selected previously, and four elders have been excluded from the third selection, since the representative sample was complete $(\mathrm{n}=384)$.

\section{Data collection}

The data was collected from July to October 2018 in domiciliary visits by the researcher and five nursing academics, who received theoretical and practical training for seven days. Instructions were provided in printed material containing the topics 1) Approaching elders using an identification badge through simple language while maintaining an ethical posture; 2) Research explanation and reading the Informed Consent Form (ICF); 3) Interview, preferably outside the house to avoid privacy invasion, and permission for the presence of a relative whenever demanded; 4) Explanation for the correct self- and interviewer-administration of LAM-VB to ensure the elder's understanding of the instructions to answer the instrument alone or to indicate the number which best represents their level of agreement with each read statement; 5) Timing for LAM-VB self- or interviewer-administration; 6) Verification of the informed data.
During collection, the academics received every day an individual list with names and addresses of elders to be interviewed; each elder was assigned a number for instrument identification. The researcher supervised one academic each day and, by the end of the period, gathered the lists and filled instruments of all group for verification and archiving to guarantee data anonymity and confidentiality.

An instrument for sociodemographic characterization (age, sex, education level, individual income, marital status, and living arrangement) elaborated by the researcher was used in addition to LAM-VB for the elderly population. Similarly to LAM, LAM-VB maintained, after cross-cultural adaptation, 36 items equally divided into cognitive, affective, and behavioral components of attitude towards leisure, with a five-point Likert-type scale as a system of response, in which " 1 " reveals an extremely negative attitude and " 5 " indicates an extremely positive attitude.

\section{DATA TREATMENT AND ANALYSIS}

The data were tabulated into a spreadsheet of the application Excel and analyzed with the program Statistical Analysis Software (SAS, version 9.4). In the descriptive analysis, the mean and standard deviation of the answers to each item were calculated.

The internal consistency of the instrument was measured with Cronbach alpha coefficient; values over 0.60 were considered acceptable due to this being an exploratory factor analysis (EFA). The construct validity of LAM-VB was evaluated through EFA after verification of sample adequacy, which used the criteria $n>100$, matrix correlation coefficients over 0.30, and Kaiser-Meyer-Olklin (KMO) test over 0.60 . The method for factor extraction was per principal components (PC), according to Kaiser criterion, i.e., eigenvalue greater than one, in addition to an analysis of the explained variance. The rotation of factors was per the orthogonal Varimax method, maintaining the items with a minimum factor loading of 0.30 . The estimate of the commonalities $\left(\mathrm{h}^{2}\right)$ was calculated accepting values greater than $0.30^{(19)}$.

\section{ETHICAL ASPECTS}

This study was approved by the Research Ethics Committee in Protocol n. 2.194.308/2017, in accordance with Resolution 466/12. All participating elders or their guardians have signed the Informed Consent Form (ICF).

\section{RESULTS}

The study participants were aged 61 to 93 , with a mean age of 70.89 years $(\mathrm{SD}=7.64)$, and were mostly female (62.76\%), married, or in domestic partnership (61.20\%), living with relatives $(86.16 \%)$, with one to four years of education $(50.52 \%)$, and a personal income of up to one minimum wage $(48.95 \%)$ (Table 1$)$. 
Table 1 - Distribution of elders participating in the study per sociodemographic characteristics - Maringá, PR, Brazil, 2018.

\begin{tabular}{lc}
\hline Variables & $\mathbf{n}(\%)$ \\
\hline Sex $(\mathbf{n}=\mathbf{3 8 4})$ & \\
Male & $143(37.24 \%)$ \\
Female & $241(62.76 \%)$ \\
\hline
\end{tabular}

Age group $(n=379)$

\begin{tabular}{lc}
60 to 69 years old & $190(50.13 \%)$ \\
70 to 79 years old & $131(34.56 \%)$ \\
$80+$ years old & $58(15.31 \%)$ \\
\hline
\end{tabular}

Marital status $(n=384)$

\begin{tabular}{lc} 
Single & $21(5.47 \%)$ \\
Married/Domestic partnership & $235(61.20 \%)$ \\
Separated & $28(7.29 \%)$ \\
Widow(er) & $100(26.04 \%)$ \\
\hline
\end{tabular}

Lives $(\mathrm{n}=383)$

\begin{tabular}{lc} 
Alone & $53(13.84 \%)$ \\
With relatives & $330(86.16 \%)$ \\
\hline
\end{tabular}

Education $(n=384)$

\begin{tabular}{lc} 
Illiterate & $45(11.72 \%)$ \\
1 to 4 years of education & $194(50.52 \%)$ \\
5 to 8 years of education & $60(15.63 \%)$ \\
9 to 11 years of education & $49(12.76 \%)$ \\
$11+$ years of education & $36(9.37 \%)$ \\
\hline
\end{tabular}

Personal income $(\mathrm{n}=380)$

None

$52(13.68 \%)$

Up to 1 minimum wage*

$186(48.95 \%)$

1 to 2 minimum wages*

$59(15.53 \%)$

2 to 3 minimum wages*

$44(11.58 \%)$

$3+$ minimum wages*

$39(10.26 \%)$

*minimum wage during data collection: R\$954.00 (BRL Brazilian Reais). Note: $(n=384)$.

The instrument LAM-VB was filled by $29.65 \%$ of the elderly and, for the rest, by the researcher/academic. In both cases, the mean time of filling was ten minutes.

In the first phase of EFA, the correlation matrix and the Cronbach alpha coefficient $(\alpha)$ were analyzed for each domain and for the global LAM-VB. The cognitive domain has presented results over 0.30 for the correlation among items and the $\alpha$ coefficient (0.85), which indicates an appropriate reliability, and has been through no significant changes in the simulation for item exclusion; thus, all 12 items were considered for the analysis. The same was true of the affective domain, for which values of correlation between the items were higher than 0.50 and the $\alpha$ coefficient (0.92) showed no relevant changes upon item exclusion (Table 2).

As for the behavioral domain, seven items have presented correlations under 0.30 and were thus excluded from the analysis after repeated verifications for the elimination of each one: 25) "I do leisure activities frequently"; 27) "I buy goods and equipment to use in my leisure activities as my income allows"; 30) "Given a choice, I would live in an environment or city which provides for leisure"; 31) "I do some leisure activities even when they have not been planned."; 32) "I would attend a seminar or a class to be able to do leisure activities better"; 33) "I support the idea of increasing my free time to engage in leisure activities"; and 36) "I give my leisure high priority among other activities". For the five retained items (Table 2), the correlation presented values over 0.30 and sufficient reliability $(\alpha=0.65)$.

For the total of 29 items retained for analysis, the $\alpha$ coefficient was 0.92 , revealing an appropriate reliability for the instrument. Also, in Table 2, all items are observed to present correlations over 0.30 and the $\alpha$ for the behavioral domain is shown to have increased from 0.60 to 0.90 , approximately, when considering the instrument as a whole.

In the second step of EFA, the extraction of factors by principal components was performed and five factors with eigenvalues $>1$ were obtained, with their respective explained variances, in decreasing order: factor $1-10.03(34.60 \%)$; factor $2-2.10$ (7.25\%); factor $3-1.76$ (6.10\%); factor $4-1.71$ (4.25\%); factor $5-1.23(3.70 \%)$. However, the parsimony of the model was considered and modelling of factors 4 and 5 was removed, as their gain for the explanation of total variability of data would be of only $7.95 \%$. The three factors together explain $47.95 \%$ of the total data variance. The sample presented an appropriate size for factor analysis and an excellent suitability of model adjustment $(\mathrm{KMO}=0.92)$.

The three domains presented factor loadings over 0.30 (Table 3), considering a sample composed of more than 350 subjects. However, when calculating the estimate of the commonalities, items one and two, which had already indicated small factor loadings, have also presented low commonalities ( 0.19 and 0.27 , respectively). The excluded items were thus 1 ) "Engaging in leisure activities is a wise use of time"; and 2) "Leisure activities are beneficial to individuals and society", and a new factor analysis was performed.

In the second extraction of factors per principal components of the instrument with 27 items, four factors with eigenvalues $>1$ were obtained, with their respective explained variances, in decreasing order: factor $1-9.69$ (35.91\%); factor $2-2.08$ (7.73\%); factor $3-1.74$ (6.45\%); factor $4-1.09$ (4.07\%). Factor 4 was removed from the analysis, considering the parsimony of the model and the small explained variance that it would add. The explanation of the total data variance through the three factors increased from $47.95 \%$ to $50 \%$ and KMO (0.92) was unchanged. For LAM-VB with 27 items, the $\alpha$ coefficient was 0.89 and for the cognitive, affective, and behavioral components, it was, respectively, $0.85,0.92$, and 0.65 .

The first factor, operationalized through the items 13 to 24 , explained $35.91 \%$ of the total data variability, which makes it the most important dimension to explain the attitudes of the elderly towards leisure, and was interpreted as being the affective domain of LAM-VB. The second factor, which encompasses the items three to 12 , explains $7.73 \%$ of data variability and was interpreted as being the cognitive domain of the instrument. The third factor, composed of the items 26, 28, 29, 34, and 35, has presented an explained variance of $6.45 \%$ and was interpreted as corresponding to the behavioral domain of LAM-VB (Table 3). 
Table 2 - Mean, standard deviation, correlation between items, and internal consistency per domain and global instrument - Maringá, PR, Brazil, 2018.

\begin{tabular}{|c|c|c|c|c|c|c|}
\hline Items & Mean & SD & $\begin{array}{l}\text { Correlation between } \\
\text { items in the domain }\end{array}$ & $\begin{array}{c}\alpha^{*} \\
\text { domain upon item } \\
\text { exclusion }\end{array}$ & $\begin{array}{l}\text { Correlation } \\
\text { item-total }\end{array}$ & $\begin{array}{c}\alpha^{*} \\
\text { global instrument } \\
\text { upon item exclusion }\end{array}$ \\
\hline \multicolumn{7}{|c|}{ Cognitive $/ \mathrm{n}=384$} \\
\hline 1 & 4.78 & 0.63 & 0.39 & 0.85 & 0.37 & 0.90 \\
\hline 2 & 4.73 & 0.70 & 0.39 & 0.85 & 0.39 & 0.90 \\
\hline 3 & 4.51 & 0.87 & 0.40 & 0.86 & 0.34 & 0.90 \\
\hline 4 & 4.80 & 0.63 & 0.60 & 0.84 & 0.49 & 0.90 \\
\hline 5 & 4.79 & 0.64 & 0.57 & 0.84 & 0.45 & 0.90 \\
\hline 6 & 4.69 & 0.80 & 0.56 & 0.84 & 0.51 & 0.90 \\
\hline 7 & 4.78 & 0.64 & 0.67 & 0.83 & 0.54 & 0.90 \\
\hline 8 & 4.60 & 0.86 & 0.51 & 0.85 & 0.49 & 0.90 \\
\hline 9 & 4.76 & 0.68 & 0.62 & 0.84 & 0.57 & 0.90 \\
\hline 10 & 4.83 & 0.57 & 0.54 & 0.84 & 0.51 & 0.90 \\
\hline 11 & 4.76 & 0.66 & 0.55 & 0.84 & 0.50 & 0.90 \\
\hline 12 & 4.87 & 0.50 & 0.69 & 0.84 & 0.63 & 0.90 \\
\hline \multicolumn{7}{|c|}{ Affective } \\
\hline 13 & 4.83 & 0.57 & 0.57 & 0.92 & 0.49 & 0.90 \\
\hline 14 & 4.75 & 0.71 & 0.72 & 0.91 & 0.61 & 0.89 \\
\hline 15 & 4.81 & 0.67 & 0.70 & 0.92 & 0.63 & 0.89 \\
\hline 16 & 4.79 & 0.67 & 0.67 & 0.92 & 0.59 & 0.89 \\
\hline 17 & 4.71 & 0.74 & 0.73 & 0.91 & 0.66 & 0.89 \\
\hline 18 & 4.84 & 0.58 & 0.77 & 0.91 & 0.67 & 0.89 \\
\hline 19 & 4.79 & 0.64 & 0.76 & 0.91 & 0.69 & 0.89 \\
\hline 20 & 4.63 & 0.85 & 0.74 & 0.91 & 0.68 & 0.89 \\
\hline 21 & 4.63 & 0.87 & 0.58 & 0.92 & 0.56 & 0.89 \\
\hline 22 & 4.81 & 0.70 & 0.67 & 0.92 & 0.57 & 0.89 \\
\hline 23 & 4.79 & 0.64 & 0.79 & 0.91 & 0.70 & 0.89 \\
\hline 24 & 4.63 & 0.84 & 0.54 & 0.92 & 0.48 & 0.90 \\
\hline \multicolumn{7}{|c|}{ Behavioral / $n=384$} \\
\hline 26 & 4.17 & 1.41 & 0.37 & 0.62 & 0.35 & 0.90 \\
\hline 28 & 4.23 & 1.37 & 0.41 & 0.60 & 0.34 & 0.90 \\
\hline 29 & 4.01 & 1.47 & 0.47 & 0.57 & 0.45 & 0.90 \\
\hline 34 & 3.65 & 1.58 & 0.39 & 0.61 & 0.37 & 0.90 \\
\hline 35 & 3.78 & 1.60 & 0.39 & 0.61 & 0.35 & 0.90 \\
\hline
\end{tabular}

* Cronbach alpha coefficient. 
Table 3 - Principal component matrix after Varimax rotation of the 27 items of LAM-VB - Maringá, PR, Brazil, 2018.

\begin{tabular}{|c|c|c|c|c|}
\hline & Item & Factor 1 & Factor 2 & Factor 3 \\
\hline \multirow{10}{*}{ Cognitive } & 3-People often develop friendships in their leisure. & -0.05 & 0.46 & 0.38 \\
\hline & 4-Leisure activities contribute to one's health. & 0.23 & 0.69 & -0.02 \\
\hline & 5-Leisure activities increase one's happiness. & 0.09 & 0.69 & 0.09 \\
\hline & 6-Leisure increases one's work productivity. & 0.23 & 0.61 & 0.12 \\
\hline & 7-Leisure activities help to renew one's energy. & 0.29 & 0.70 & -0.03 \\
\hline & 8-Leisure activities can be a means for self-improvement. & 0.23 & 0.51 & 0.19 \\
\hline & 9-Leisure activities help individuals to relax. & 0.29 & 0.62 & 0.17 \\
\hline & 10-People need leisure activities. & 0.30 & 0.45 & 0.08 \\
\hline & 11-Leisure activities are good opportunities for social contacts. & 0.19 & 0.58 & 0.26 \\
\hline & 12-Leisure activities are important. & 0.44 & 0.63 & 0.07 \\
\hline \multirow{13}{*}{ Affective } & 13-When I am engaged in leisure activities, the time flies. & 0.60 & 0.20 & 0.03 \\
\hline & 14-My leisure activities give me pleasure. & 0.75 & 0.20 & 0.08 \\
\hline & $15-$ I value my leisure activities. & 0.71 & 0.30 & 0.03 \\
\hline & 16-I can be myself during my leisure. & 0.69 & 0.17 & 0.17 \\
\hline & 17-My leisure activities provide me with delightful experiences. & 0.73 & 0.23 & 0.18 \\
\hline & 18 -I feel that leisure is good for me. & 0.77 & 0.25 & 0.12 \\
\hline & 19-I like to take my time while I am engaged in leisure activities. & 0.74 & 0.30 & 0.18 \\
\hline & 20-My leisure activities are refreshing. & 0.71 & 0.22 & 0.25 \\
\hline & 21-I consider it appropriate to engage in leisure activities frequently. & 0.55 & 0.28 & 0.19 \\
\hline & $22-I$ feel that the time I spend on leisure activities is not wasted. & 0.70 & 0.22 & 0.00 \\
\hline & 23-I like my leisure activities. & 0.79 & 0.25 & 0.15 \\
\hline & 24-My leisure activities absorb or get my full attention. & 0.61 & -0.05 & 0.28 \\
\hline & 26-Given a choice I would increase the amount of time I spend in leisure activities. & 0.02 & 0.25 & 0.59 \\
\hline \multirow{4}{*}{ Behavioral } & 28-I would do more new leisure activities if I could afford the time and money. & 0.05 & 0.15 & 0.63 \\
\hline & 29-I spend considerable time and effort to be more competent in my leisure activities. & 0.26 & 0.10 & 0.62 \\
\hline & 34-I engage in leisure activities even when I am busy. & 0.22 & 0.03 & 0.56 \\
\hline & $35-$ I would spend time in education and preparation for leisure activities. & 0.17 & 0.00 & 0.62 \\
\hline
\end{tabular}

Overall, $7.40 \%$ of the factor loadings for the items had average values (from 0.30 to 0.50 ), $66.67 \%$ presented moderate values (from 0.50 to 0.70 ) and $25.93 \%$ obtained high values (over 0.70). In factor 1 (affective domain), the factor loadings ranged from 0.55 (item 21) to 0.79 (item 23); in factor 2 (cognitive domain), the variation was from 0.45 (item 10) to 0.70 (item seven); finally, in factor 3 (behavioral domain), 0.56 (item
34) and 0.63 (item 28) were the lowest and the highest factor loadings, respectively. No item was observed to have a factor loading weighing in more than one factor with difference $<0.15$.

Since two items have been excluded due to low communality values, what indicates that these items were not linearly correlated to the group of the variables of the factor, these variables were recalculated (Table 4).

Table 4 - Estimated communalities for the items considered in the LAM-VB - Maringá, PR, Brazil, 2018.

\begin{tabular}{|c|c|c|c|c|c|c|c|c|c|c|c|c|}
\hline \multicolumn{13}{|c|}{ Cognitive } \\
\hline Items & 1 & 2 & 3 & 4 & 5 & 6 & 7 & 8 & 9 & 10 & 11 & 12 \\
\hline$h^{2 *}$ & $* * *$ & $* * *$ & 0.36 & 0.53 & 0.49 & 0.44 & 0.58 & 0.35 & 0.50 & 0.36 & 0.43 & 0.60 \\
\hline \multicolumn{13}{|c|}{ Affective } \\
\hline Items & 13 & 14 & 15 & 16 & 17 & 18 & 19 & 20 & 21 & 22 & 23 & 24 \\
\hline $\mathbf{h}^{2 *}$ & 0.40 & 0.61 & 0.59 & 0.53 & 0.62 & 0.67 & 0.66 & 0.62 & 0.41 & 0.55 & 0.70 & 0.45 \\
\hline \multicolumn{13}{|c|}{ Behavioral } \\
\hline Items & 25 & 26 & 27 & 28 & 29 & 30 & 31 & 32 & 33 & 34 & 35 & 36 \\
\hline $\mathbf{h}^{2 *}$ & $* *$ & 0.42 & $* *$ & 0.42 & 0.46 & $* *$ & $* *$ & $* *$ & $* *$ & 0.36 & 0.41 & $* *$ \\
\hline
\end{tabular}


After reanalysis, all items reached desirable results, i.e., over 0.30 .

\section{DISCUSSION}

The factor structure and the reliability of LAM-VB have been evaluated and the instrument was noticed to present appropriate psychometric properties in its application to the studied sample of elders, which makes it a useful tool for Brazilian studies on leisure. LAM-VB was applied as self- and interviewer-administered. The advantages of self-administration include saving resources, mainly when applying online questionnaires, in addition to eliminating interviewer bias; on the other hand, it may be faced with obstacles due to interviewee bias, mainly among participants with reading difficulties ${ }^{(20)}$.

The values of the Cronbach alpha coefficient for the global instrument and for the three domains have shown a satisfactory reliability for LAM-VB. The values are more similar to those found in the reduced Portuguese version of $\mathrm{LAM}^{(13)}$, for which the coefficient was 0.88 in the global instrument and 0.81, 0.85, and 0.76 in the cognitive, affective, and behavioral domains, respectively, than those of the original version ${ }^{(17)}$, in which 0.94 was obtained in the global assessment and 0.91,0.93, and 0.89 in the cognitive, affective, and behavioral domains, in this order. The behavioral domain has shown the smallest coefficient, a finding which also corroborates the original Portuguese ${ }^{(17)}$ and reduced $^{(13)}$ versions of LAM. This is believed to be due to the heterogeneity in the composition of the items of this domain ${ }^{(17)}$ and may indicate a weak association between attitude and behavior, suggesting that the attitude results of affective and cognitive reactions and which reflects behavioral intentions, but does not predict behavior ${ }^{(13)}$.

The low correlations have led to an empirical analysis ${ }^{(19)}$ for the exclusion of seven items of the behavioral domain. Considering the similarities between the languages, the reduced Portuguese version of LAM was observed to maintain six items in this domain ${ }^{(13)}$, supported by factor loadings over 0.50 and, out of these, four corresponded to items which were also maintained in LAM-VB. The two items maintained in the first and excluded from the second were related to individual disposition to watch a class or seminar to better conduct their leisure activities and to the prioritization of leisure among their activities. One item, which refers to the increase in the frequency of leisure given a higher availability of time and money, was maintained in LAM-VB and excluded from the Portuguese reduced version.

These differences may be explained by the fact that the Portuguese version was aimed at young students whereas the Brazilian version was aimed at the elderly. Indeed, the education level and the income of most elders in this research suggest that leisure is not related to the understanding of theoretical knowledge or prioritizing of activities, but to time management and availability of financial resources, frequent conditions in retirement, a phase characterized by the interruption of labor activities ${ }^{(6-7)}$.

The structural assessment was continued with the employment of EFA instead of confirmatory factor analysis (CFA), although this is an adapted instrument, considering that there is no previous empirical evidence specifically for the characteristics of the selected sample ${ }^{(21-22)}$. The model has shown an appropriate suitability for EFA through KMO test after adjustments. The sample, comprising 384 cases, seemed to meet the presuppositions for the tested instrument, since, out of 27 communalities, five presented a value under 0.4 and, out of three factors, two had more than six items. The literature reports the need for a sample of 400 subjects for commonalities around 0.30 and factors with three items; 200 subjects for commonalities between 0.40 and 0.70 and factors with three to four items; or from 150 to 200 subjects for factor loadings over 0.70 and at least six items per factor ${ }^{(22)}$.

The factors were extracted through the $\mathrm{PC}$ technique and Varimax rotation was employed. The rotation of the axes enables any factor to be found, making the solution arbitrary; thus, a theory to support latent trait is required for rotation to work as hypothesis test and not as fishing for them ${ }^{(19)}$. The selection of factors to be retained in the analysis was based on the Kaiser rule and on the parsimony model and was determinant, since the insufficiency of factors would lead to the difficulty of interpretation of factor loadings and exceeding factors would create domains with little theoretical meaning ${ }^{(22)}$. The analysis of this research has supported the factors of the original version, but in the versions of Korea and China, for example, structures with four factors were found ${ }^{(13)}$.

The factor loading values were found to be predominantly moderate. A minimum value of 0.30 and a difference over 0.15 between the factor loadings of the same item for the existing factors is recommended ${ }^{(21)}$. Concerning the commonalities, which estimate the part of variance of each item explained by the common underlying factor, two items have presented values under 0.30 in the first EFA, suggesting their elimination.

From an empirical point of view, the understanding of leisure as effective time (item one) and as a beneficial practice for the whole society (item two) did not seem to conform with the rest of the domain. In both, the sociocultural context must be considered. The decision of excluding items implies a reanalysis for each eliminated item, since small variations may substantially modify the final result of the analysis ${ }^{(21-22)}$.

In the first case, the work-leisure duality and the obsolete concept of idleness may explain the issue of effective time, since, for the elderly, there may be the understanding that effective time is spent at work, which is overvalued in relation to leisure ${ }^{(2)}$. In the second situation, conceptions of enjoyment postulated in contemporary society, related to devious activities, such as alcohol and drug abuse ${ }^{(23)}$, may have led to a conflict with the conception of leisure for the elderly, which is subjective, making measuring this item difficult. To change such perspectives, developing educational interventions for leisure would be ideal ${ }^{(8)}$ as these are still rudimentary in Brazil.

Although conserving three factors in the factor structure, LAM-VB has presented a shortened conformation in relation to the original version ${ }^{(17)}$, with 10,12 , and 5 items in the cognitive, affective, and behavioral domains, respectively, and 27 items in the global instrument, whose construct validity and reliability were satisfactory, which shows the influence of cultural factors on the construct; thus, this construct is expected to manifest differently in different cultures ${ }^{(15)}$. The adopted solution seemed to be the 
most appropriate for the studied population, but it must be reevaluated in further research.

The present study has methodological limitations. The selected sample does not represent Brazilian elders in general, but those of the municipality in which the data was collected. The use of a Likert-type scale for calculating the score characterizes qualitative and polytomous variables, whereas the Pearson correlation matrix requires continuous variables and presupposes linear relations; this does not invalidate the results, considering the model suitability test. Test-retest reliability was not performed for assessing possible statistical differences between self- and interviewer-administration of LAM-VB. In addition, CFA is recommended to confirm the presented factor structure.

\section{CONCLUSION}

The results of this study proposed a structural model for LAM-VB which preserves three factors under the parsimony criterion and explains $50 \%$ of data variance and the appropriate suitability of model adjustment $(\mathrm{KMO}=0.92)$. For the total 27 items of the final model, the $\alpha$ coefficient was 0.89 for the global instrument and $0.85,0.92$, and 0.65 for the cognitive, affective, and behavioral domains, respectively. The instrument can be administered in its current format, but complementary studies with distinct populations in Brazil and other psychometric tests are recommended to consolidate the instrument and guarantee its reproducibility.

Since this is an adapted tool, LAM-VB may be compared in multicenter projects with instruments for other cultures. Concerning nursing practice, LAM-VB may help, within collective health, to raise indicators for the assessment and monitoring of health promotion actions, as well as to understand social reality. The development of educational strategies for leisure may transform beliefs and feelings of the elderly on this phenomenon and shape their global orientation towards life, aiming at fostering a positive attitude and facilitating their involvement in leisure activities.

\section{RESUMO}

Objetivo: Avaliar a validade de constructo e a consistência interna da versão brasileira da Leisure Attitude Measurement para a pessoa idosa. Método: Estudo metodológico, de abordagem quantitativa. Os dados foram coletados durante três meses, por meio de visitas domiciliares, em amostra aleatória e representativa de 384 idosos. A consistência interna foi medida pelo coeficiente alfa de Cronbach. A validade de constructo foi avaliada pela análise fatorial exploratória. A extração dos fatores foi realizada por componentes principais, segundo o critério de Kaiser, com rotação pela solução Varimax. Resultados: Os participantes tinham em média 70,9 anos e eram, na maioria, mulheres, casados, residentes com familiares, com um a quatro anos de estudo e renda de até um salário mínimo. O modelo final do instrumento conservou três fatores, sob o critério da parcimônia, explicando $50 \%$ da variância dos dados, com 27 itens totais, distribuídos nos domínios cognitivo, afetivo e comportamental e com coeficiente alfa de Cronbach global de 0,89. Conclusão: O modelo estrutural proposto mostrou validade de constructo e consistência interna adequada e explicou $50 \%$ da variabilidade dos dados. Sua aplicação permitirá conhecer a realidade social e incentivar atitude positiva e engajamento de idosos no lazer.

\section{DESCRITORES}

Idoso; Atividades de Lazer; Qualidade de Vida; Saúde do Idoso; Enfermagem Geriátrica; Estudo de Validação.

\section{RESUMEN}

Objetivo: Evaluar la validez de constructo y la consistencia interna de la versión brasileña de la Leisure Attitude Measurement para los ancianos. Método: Estudio metodológico con enfoque cuantitativo. Los datos se recogieron durante tres meses, mediante visitas a domicilio, en una muestra aleatoria y representativa de 384 ancianos. La consistencia interna se midió mediante el coeficiente alfa de Cronbach. La validez de constructo se evaluó mediante el análisis factorial exploratorio. La extracción de factores se realizó por componentes principales, según el criterio de Kaiser, con rotación por solución Varimax. Resultados: Los participantes tenían una media de edad de 70,9 años y en su mayoría eran mujeres, casados, vivían con familiares, con entre uno y cuatro años de escolaridad e ingresos de hasta un salario mínimo. El modelo final del instrumento retuvo tres factores, bajo el criterio de parsimonia, explicando el $50 \%$ de la varianza de los datos, con un total de 27 ítems, distribuidos en los dominios cognitivo, afectivo y comportamental y con un coeficiente alfa de Cronbach global de 0,89. Conclusión: El modelo estructural propuesto mostró validez de constructo y consistencia interna adecuada y explicó el $50 \%$ de la variabilidad de los datos. Su aplicación permitirá conocer la realidad social y fomentar la actitud positiva y la participación de los ancianos en el ocio.

\section{DESCRIPTORES}

Anciano; Actividades Recreativas; Calidad de Vida; Salud del Anciano; Enfermería Geriátrica; Estudio de Validación.

\section{REFERENCES}

1. Andrade RD, Schwartz GM, Tavares GH, Pelegrini A, Teixeira CS, Felden EPG. Construct validity and internal consistency in the Leisure Practices Scale (EPL) for adults. Ciênc Saúde Coletiva. 2018;23(2):519-28. doi: http://dx.doi.org/10.1590/1413-81232018232.11492016.

2. Roscoche LF. Trabalho, lazer e religião: uma aproximação. Licere. 2016;19(2):388-420.

3. Castro VC, Carreira L. Leisure activities and attitude of institutionalized elderly people: a basis for nursing practice. Rev Latino Am Enferm. 2015;23(2):307-14. doi: http://dx.doi.org/10.1590/0104-1169.3650.2556

4. Michèle J, Guillaume M, Alain T, Nathalie B, Claude F, Kamel G. Social and leisure activity profiles and well-being among the older adults: a longitudinal study. Aging Ment Health. 2019;23(1):77-83. doi: http://dx.doi.org/10.1080/13607863.2017.1394442

5. Afshar PF, Foroughan M, Vedadhir A, Tabatabaie MG. Psychometric properties of the Persian Version of Social Adaptation Self-evaluation Scale in community-dwelling older adults. Clin Interv Aging. 2017;12:579-84. doi: http://dx.doi.org/10.2147/CIA.S129407

6. Pissinati PSC, Haddad MCFL, Munari DB, Martins JT, Gvozd R. Aptitude for behavior change in the planning of retirement in preretirement workers. Ciênc Cuid Saúde. 2017;16(3):1-7. doi: http://dx.doi.org/10.4025/cienccuidsaude.v16i3.38310

7. Lee C, Payne LL, Berdychevsky L. The roles of leisure attitudes and self-efficacy on attitudes toward retirement among retirees: a sense of coherence theory approach. Leisure Sci. 2020;42(2):152-69. doi: http://dx.doi.org/10.1080/01490400.2018.1448025 
8. Kao IC, Chang LC. Long-term effects of leisure education on leisure needs and stress in older adults. Educ Gerontol. 2017;43(7):356-64. doi: http://dx.doi.org/10.1080/03601277.2017.1299447

9. Earl JK, Gerrans P, Halim VA. Active and adjusted: Investigating the contribution of leisure, health and psychosocial factors to retirement adjustment. Leisure Sci. 2015;37(4):354-72. doi: http://dx.doi.org/10.1080/01490400.2015.1021881

10. Ribeiro DKMN, Lenardt MH, Michel T, Setoguchi LS, Grden CRB, Oliveira ES. Contributory factors for the functional independence of oldest old. Rev Esc Enferm USP. 2015;49(1):89-96. doi: https://doi.org/10.1590/S0080-623420150000100012

11. Dattilo J, Lorek A, Mogle J, Sliwinski M, Freed S, Frysinger M, et. al. Perceptions of leisure by older adults who attend senior centers. Leisure Sci. 2015;37(4):373-90. doi: http://dx.doi.org/10.1080/01490400.2015.1016563

12. Kim J, Irwin L, Kim M, Chin S, Kim J. The role of leisure engagement for health benefits among Korean older women. Health Care Women Int. 2015;36(12):1357-74. doi: http://dx.doi.org/10.1080/07399332.2015.1077843

13. Teixeira A, Freire T. The Leisure Attitude Scale: psychometrics properties of a short version for adolescents and young adults. Leisure Loisir. 2013;37(1). doi: http://dx.doi.org/10.1080/14927713.2013.776748

14. Martínez-Rodríguez S, Iraurgi I, Gómez-Marroquin I, Carrasco M, Ortiz-Marqués N, Stevens AB. Psychometric properties of the Leisure Time Satisfaction Scale in family caregivers. Psicothema. 2016;28(2):207-13. doi: http://dx.doi.org/10.7334/psicothema2015.278

15. Ferreira HG, Barham Ej. Estrutura fatorial da versão brasileira do california older person's pleasant events Schedule. Aval Psicol. 2017;16(4):405-14. doi: http://dx.doi.org/ 10.15689/ap.2017.1604.12627

16. Streiner DL, Kottner J. Recommendations for reporting the results of studies of instrument and scale development and testing. J Adv Nurs. 2014;70(9):1970-9. doi: http://dx.doi.org/10.1111/jan.12402

17. Ragheb MG, Beard JG. Measuring Leisure Attitude. J Leis Res. 1982;14(2):155-67. doi: https://doi.org/10.1080/00222216.1982.11969512

18. Brucki SMD, Nitrini R, Caramelli P, Bertolucci PHF, Okamoto IH. Sugestões para o uso do mini-exame do estado mental no Brasil. Arq Neuro Psiquiatr. 2003;61(3B):777-81. doi: http://dx.doi.org/10.1590/S0004-282X2003000500014

19. Hair Jr JF, Black WC, Babin BJ, Anderson RE. Multivariate data analysis. London: Pearson; 2014.

20. Chu AHY, Ng SHX, Koh D, Müller-Riemenschneider F. Reliability and validity of the self- and interviewer-administered versions of the Global Physical Activity Questionnaire (GPAQ). PLoS One. 2015;10(9):e0136944. doi:10.1371/journal.pone.0136944

21. Reichenheim ME, Hokerberg YHM, Moraes CL. Assessing construct structural validity of epidemiological measurement tools: a seven-step roadmap. Cad Saúde Pública. 2014;30(5):927-39. doi: http://dx.doi.org/10.1590/0102-311X00143613

22. Lloret-Segura S, Ferreres-Traver A, Hernández-Baeza A, Tomás-Marco I. El análisis factorial exploratorio de los ítems: una guía práctica, revisada y actualizada. An Psicol. 2014;30(3):1151-69. doi: http://dx.doi.org/10.6018/analesps.30.3.199361

23. Stodolska M, Berdychevsky L, Shinew KJ. Gangs and deviant leisure. Leisure Sci. 2019;41(4):278-93. doi: http://dx.doi.org/10.1080/014 90400.2017.1329040 